\title{
PHYSIOTHERAPY IN RELATION TO ORTHOPAEDIC SURGERY IN THE TREATMENT OF CEREBRAL PALSY \\ by
}

\section{THE PHYSIOTHERAPY DEPARTMENT}

\author{
(A. MATHIAS, B.Sc. (Physio) Wits \\ SENIOR PHYSIOTHERAPIST)
}

\author{
FOREST TOWN SCHOOL FOR CEREBRAL PALSIED CHILDREN, \\ JOHANNESBURG.
}

\section{SUMMARY}

1. Introduction.

(a) The Integration of the Orthopaedic Approach with other techniques used.

(b) Preparation for hospitalisation.

2. Physiotherapy in Relation to Specific Surgical Procedures.

3. Note on the Forest Town Boot.

4. References.

\section{SUMMARY}

Physiotherapy in relation to Orthopaedic Surgery in the treatment of Cerebral Palsy.

Orthopaedic Surgery is an integral part of the treatment of cerebral palsy; the success of such surgery being largely dependent on the pre- and post-operative therapy which the patient receives. A format of physiotherapy which decreases post-operative disturbance and enhances the results of surgery has been developed at the Forest Town School for Cerebral Palsied Children and is described as it pertains to surgery of the lower extremities.

The Integration of the Orthopaedic Approach with other techniques used in the Treatment of Cerebral Palsy.

Physiotherapy has been used in the treatment of Cerebral Palsy since the time that treatment was directed towards it as a specific condition. The role of physiotnerapy has varied with the passage of time. At first, it was considered to be the only treatment indicated, albeit used in conjunction with braces, by Winthrop Phelps, who also advocated the "Team Approach" (Keats, "Cerebral Palsy"-Thomas 1965).

Different techniques or approaches to the physiotherapeutic treatment of Cerebral Palsy became established and are fully described in the literature. (American Journal of Physical Medicine, Vol. 46, No. 1, February 1967).

Orthopaedic surgery, when it first entered the field, was used as a substitute treatment, disregarding physiotherapy, with disastrous results from the orthopaedic angle. It is now appreciated that the success of surgery is largely dependent on the quality of therapy which the patient receives, and orthopaedic surgery and bracing is now an integral part of the treatment of the cerebral palsied. The physiotherapist shares the responsibility for the state of the patient.

However, there still exists a great deal of confusion and doubt as to the role of orthopaedic surgery, among therapists working in the field. This is mainly due to the fact that some exponents of accepted treatment tech-

\section{OPSOMMING}

Fisiaterapie met betrekking tot Ortopediese Chirurgie in die behandeling van Serebrale Verlamming.

Ortopediese Chirurgie is 'n integrale deel van die behandeling van serebrale-verlamming; en die sukses van sulke chirurgie is grootendeels afhanklik van die meegaande terapie wat die pasiënt ontvang. 'n Vormaat van fisioterapie wat die navolgende steurnis van chirurgie verminder en die voordele daarvan verbreed is ontwikkel op Forest Townskool vir Serebraal Verlamde Kinders en word beskry met betrekking tot chirurgie van die onderste ledemate.

niques have, in the past, condemned the use of orthopaedic measures in this regard. In addition, there are certain difficulties in treating post-operative cases which may prove hazardous to the inexperienced therapist.

There is as yet, very little in the literature to guide the therapist in this aspect of treatment.

During the past fifteen years we have developed format of physiotherapy which is used in the treatment of cerebral palsied children and adults undergoing surgery, which largely eliminates permanent post-operative complications and ensures maximal success.

At Forest Town School an eclectic approlach to therapy is employed, rather than strict adherence to any one technique. The type of treatment used is dependent on the particular requirement of the child at any neurodevelopmental stage and on the type of disability (i.e. the patho-physiology). Some children respond best to a specific technique while others require a combination of techniques to achieve the best results.

Thus a baby without head control and uninhibited abnormal reflexes would respond best to the Bobath technique using reflex inhibiting patterns and facilitation of normal responses, while in the same child arm weightbearing might be achieved by using techniques of sensory stimulation to the extensors of the arm as advocated by Rood.

In an older child, however, where co-operation may be enlisted, Proprioceptive Neuromuscular Facilitation could play an important part in the breaking down of 
hnormal synergies provided that due regard is given to abnourological aspect of the child's condition-and the neureful positioning is important when using this technique.

In the same way as physiotherapy has been adapted to meet the needs of the cerebral palsied child, so has the meet the dic approach been tempered to suit their parorthopaedic approach thus orthopaedic assessment must ticular problems. account the general neurological connaturally the child and the effect that surgery or splintage will have upon this.

The integration of the orthopaedic approach with other aspects of therapy presents minimal problems when all aspects of the team are aware of all aspects of the child's condition. This includes not only the orthopaedic child neurological facets, but also educational and emotional problems which present themselves in the cerebral palsied child.

One of the basic principles in the treatment of cerebral palsy is the understanding and accurate assessment of the abnormal synergic patterns and therapy is directed the ards modifying or changing these patterns in order tow achieve as normal or as functional a pattern as ossible. However, due to intractable spasm, or where an abnormal synergy cannot be inhibited in a functional position (e.g. as in a persistent exaggerated positive supporting refiex producing equinus of the foot), normal development is even further impaired. Here the orthopaedic approach, whether it be conservative (i.e. bracing, "New Concepts in Bracing in Cerebral Palsy" by Alice L. Garrett, M.D. et al. Physical Therapy, July 1966, Vol. 46 No. 7) or operative, is often the most dynamic method of facilitating normal development.

By way of example, a child who is unable to develop standing balance due to a persistent exaggerated Positive Supporting Reaction producing equinus could be considerably helped by wearing the Forest Town Boot, which will enable him to stand on a plantigrade foot. e.g. Case I.

'Carel, spastic quadriplegic, is more affected on the Right than on the Left. He was pulling up to standing at 15 months, but he was unable to learn to stand alone because of bilateral equinus feet. After wearing Forest Town Boots, he walked at 20 months, for the following six months, he could stand and walk while wearing the Forest Town Boots, but not without them.'

In addition the effect of the Positive Supporting Reflex could be overcome by putting the triceps surae muscles at a mechanical disadvantage as is achieved by a gastrocnemius recession and T.A.Z-lengthening operation.

The correction of deformities and contractures may enable a sedentary child to become upright and mobile and the psychological importance of this achievement cannot be over-estimated. Moreover, the educational aspect of the child's development is also enhanced as the experience of the upright position plays an important part in the awarness of spatial orientation and hence in perceptual development. The improvement in body image and the subsequent perceptual concepts brought about by the attainment of the upright position has been repeatedly observed.

A particular example is of a child who, in the "Drawa-man" test would produce a picture of a man either lying down or with no particular relationship to the upright while the limbs showed no constant orientation. Post-operatively and following mobilization, she drew a man standing upright and on his feet.

In addition, increased mobility attained by surgery enables the child to explore his environment and thus learn new spatial concepts which he was unable to grasp beforehand.

Successful integration of the orthopaedic approach with other techniques used depends mainly on a close co-operation between surgeon and therapists. Surgery is never performed in isolation - all members of the team including the teachers are aware of the aims, purposes and possible problems of surgery. Post-operatively, a change of positioning in the classroom may be indicated as well as an adaption to classroom furniture.

The emphasis in therapy may be changed by surgery. Changes in pattern produced by surgery, if not anticipated, could cause alarm. However, with the therapist well aware of this, the opposite pattern which may be produced can be immediately counteracted before it has a chance to take over or cause any kind of stress.

In the use of the Rood technique therapists have realised the need for carefully thought out methods of splintage. It is important to be aware of certain neurophysiological principles in onder to know which muscles are being facilitated and which are being inhibited by the splint used; and thus methods of sensory stimulation as advocated by Rood may be achieved by the splintage itself or superimposed on the particular method of splintage used.

The orthopaedic technician participates as a valuable member of the team and his awareness of the special problems of the Cerebral Palsied child along with his close co-operation with the surgeon and therapist enables him to adapt and modify orthopaedic appliances in such a way that the optimal support, correction and mobility can be achieved.

It has been shown that the orthopaedic approach to the treatment of the cerebral palsied child is, in our experience at Forest Town, an essential modality to supplement and complement the overall treatment and management of the child.

\section{Preparation for Hospitalisation}

\section{Outline of the procedure which has evolved at Forest}

Town

At Forest Town all staff members co-operate and participate in the preparation of a child for surgery. It is appreciated that there can be a great deal of emotional trauma to both parents and child unless this aspect is carefully and frankly handled. Basic to the success of any methods which may be employed is the general attitude towards surgery (on the part of the staff) which is inevitably communicated to the parents and children. At Forest Town, in many cases, surgery is regarded as an indispensable modality which contributes to the child's general progress, rather than a method which is considered a last resort in the case of failure of therapy. Thus parents understand, right from the beginning, that should surgery be recommended it would benefit the child, whether the aim was limited to cosmesis or to increased function.

\section{Staff and Parents}

Preparation of the child for hospitalisation starts with the members of staff handling the child and then with the parents, then staff and parents together, prepare the child.

1. It is imperative that all members of the team are fully acquainted with the type of procedure to be undertaken and the reasons for its being selected as part of the treatment programme.

2. The teaching staff who, will forfeit a certain amount of valuable time in the classroom, are aware that surgery aims to benefit the child as a whole and thus consider the time lost in the classroom is justified by the overall benefit gained. (Parents, too, understand that at this particular stage surgery takes precedence over schooling.)

3. Staff members and parents must be aware of the possible post-operative disturbances, the reasons for them and how to counteract them. These may include changes in: 
(a) response level,

(b) emotional level,

(c) altention span,

(d) the amount of pain, fatigue or fear.

The change usually consists of a depression of the first three and an increase in ' $d$ '.

(e) there will be a change in the physical condition and the child's abilities-this may initially appear to be negative, or retrogressive.

It is important to note, however, that the duration and intensity of these disturbances vary tremendously and in our experience the disturbances are inversely proportional to the thoroughness of the preparation for hospitalisation and not dependent on other factors, e.g. the severity of the operation. (Reynell 1965)

It has been repeatedly observed that children who have to be admitted for a second or even third procedure react with less disturbance than they did the first time.

4. The surgeon interviews the parents personally and explains as fully and simply as possible to them and the child, what will be achieved by the operation, what period of hospitalisation to expect and what post-operative care will be necessary at home. The importance of intensive post-operative therapy is also stressed and the fact that they must be prepared for the child to wear an orthopaedic appliance for some time after the operation. It is also pointed out that with the removal of the more obvious deformity or disability, other already present but less obvious problems may become more apparent and need further correction. There is no promise of a cure.

\section{Approach to the Child}

Preparation for hospitalisation varies with the age of the child and the emotional disposition.

The pre-verbal child (up to $2 \frac{1}{2}$ years) needs the support of its mother during hospitalisation and, ideally, the mother should accompany the child. However, few children are subjected to surgery at this age. With the guidance of the psychologist, it is determined whether the child can cope emotionally with hospitalisation. Should there be doubt in this respect, the operation is postponed, until conditions are more favourable.

\section{Preparation through play}

In the Nursery School, preparation takes the form of "Hospital Play". There is a "hospital corner" in which the dolls are dressed as nurses. patients and doctors and plastic hospital utensils are at hand. The teacher tells a story around this theme and the children participate in lively discussion and play. Throughout the school this is reinforced and the children often indulge in spontaneous "hospital play" in the playground.

\section{The School-Treatment Centre Environment}

Children see and know other children who have undergone surgery and benefited from it. They learn to accept therapists, doctors and the clinical atmosphere as much as part of life as teachers and classrooms. Others wearing and walking in plaster of paris are a familiar sight! A prospective patient is also shown the plaster saw and cutters and thus the removal of his own plaster (usually done at school) is not a completely new and frightening experience.

Clinics are held at school and the surgeons are familiar and friendly figures who inspire confidence. Older children are given opportunities to talk to the surgeon and to discuss any aspect which may be causing concern. Familiarity with the surgeon and therapists obviates the necessity for play therapy with the psychologist; however, should there be any indications of alarm, the psychologist is asked to help the parents and child and advises the surgeon and therapists in his respect.

The therapist shows the child some of the exercises he will have to do at hospital or at home and explains that the aim of the operation-"to make it easier for you th walk"-will not necessarily be immediately achieved but will surely follow on preliminary mobilization. The same physiotherapist is responsible for the child The operatively and thus the child is secure in the knowled. that he will be back with someone he knows and the
continuity of treatment is maintained.

\section{Liaison with Hospital Staff}

Because of a good liaison with the hospital staff, the nurses are aware of the special problems of the cerebral palsied child.

It is particularly important for the nurses to know how much the child can understand and communicate, to have an indication of his I.Q. and to be aware of the fact that a non-verbal child might well comprehend more than one realises.

The senior physiotherapist attends the ward round the day after the child is admitted, immediately prior to surgery. It has been found that the presence of a known doctor and familiar therapist makes a tremendous dif ference to the security of the child in the strange hospif surroundings. Should the child be unduly nervous the therapists will be present when he is taken to the theatre and stays until he is anaesthetised. The parents are present when he comes round.

The period of hospitalisation is naturally reduced to a minimum and the parents, who are well instructed as to how to care for him at home, know that he may go home as soon as his condition permits.

\section{Conclusion.}

The success of surgery is largely dependent on the thorough preparation of the child beforehand. To achieve this, all members of the team and the parents must be thoroughly acquainted with the purpose and nature of the hospital treatment to be undertaken. The child's emotional disposition is taken into account and handled with the utmost care. It is important to recognise the child's feelings about the situation-that he may be frightened or angry. The child must know that his feelings are understood and accepted and that his problems are very real. Rather than belittling his problems, he must be given support to cope with them.

\section{Physiotherapy in Relation to Orthopaedic Surgery of the Lower Extremities in Cerebral Palsy}

\section{General pre-operative measures, to be followed in d.. cases.}

These are generally the same as those used in conservative therapy when surgery is not indicated, and include the following:

1. Facilitation and training of postural reactions (balance and equilibrium) in all developmental sequences. ${ }^{* 1}$

The following secondary responses are desirable for good results post-operatively:

$i$. Head control in all positions.

ii. Hand support.

iii. Protective reactions of arms.

iv. Equilibrium reactions in lying and sitting, possibly in supported standing.

v. Reciprocal stepping movements of legs.

The presence of primitive reflexes is a deterrent to surgery but does not necessarily preclude satisfactory results. In actual fact, surgery may be an aid to the inhibition of a primitive reflex by facilitating more normal 
movement; e.g. a persistent Moro reflex may be triggered a pulling a sitting child into extenfrom tight haming of hamstrings with release of adducion. Leng in a wider sitting base with resultant imtors results balance and the ability to inhibit the Moro proved balance and 2.

roflex. e.g. Caserely involved spastic quadriplegic at six Iohan, was unable to sit in any position due to yuars old. Moro reaction. He had threatened dislocacontinu the hips as a result of contractures of adductor tion of the muscles and had surgical correction of these and psoas me could sit, learnt to deforit the Moro-reflex action and learnt to hold on with his hands, even pushing a walker.

2 Establishment of maximal joint mobility and tability permitted by deforming forces.

3. Adjustment by patient to regime which will follow post-operatively.

4. Establishment of rapport with patient and parents.

5. Preparation of patient and parents for hospitalisain and the effects thereof. *2

6. Assessment of patient as regards:

(a) emotional reaction to surgery and hospitalisation,

(b) anticipated change in patterns of movement and/or spasticity,

following surgery, e.g. (i) Pre-operative adductor spasm may mask lesser degree of spasticity in abductors of hip, with consequent over-action of abductors following adductor transfer. (ii) Pre-operative pattern of hip and knee extension, adduction and equinus of feet caused by positive supporting reflex, may change to complete flcxion after lengthening of triceps surae, due to weak spastic extensors of knee and 'breaking up' of total extensor pattern.

Therefore pre-operatively, strengthen voluntary extension, even though extensor spasticity is present.

7. Preparation of appliances which are to be used post-operatively.

8. The therapist should have a good understanding of the indications, aims and procedures of surgical treatment of the cerebral palsied. $* 3$

9. An appreciation, on the part of the therapist, of any changes occurring in the patient's condition which may necessitate early consultation with the surgeon, e.g. (i) a complaint of pain in the hips, which may indicate threatening subluxation, or (ii) the development of a "rocker-bottom" foot, (iii) development of pelvic obliity with possible development of scoliosis.

\section{General Post-operative Measures}

\section{Immediate post-operative period}

(a) During this time the patient is sedated; to relieve pain and spasm. After the first few days spasm only may need to be prevented; and valium is usually prescribed for this purpose.

(b) Nursing postures should be corrected to prevent abnormal reflex spasticity, e.g. the head should be in the mid-line and slightly flexed forward to prevent extensor spasm in many cases, or flexor spasm of the legs in patients with a residual symmetrical tonic neck reflex.

(c) Prevention of pressure sores.

(d) Therapy given while patient is in plaster includes: (i) Maintenance of upper extremity mobility and strength

(ii) Abdominal and hip extension exercises, also abduction when not in a spica.

(iii) Maintenance of foot movement when possible.

(e) Routine post-operative chest care.

\section{Removal of Plaster of Paris}

(a) Minimise apprehensions and fear by giving a suitable sedative, and by the presence of a familiar therapist during actual removal of plaster.

(b) Prevent any untoward movement of the limb by preventing and controlling spasm.

(c) Give adequate skin care.

(d) Check appliances. N.B. Retain plaster of paris backslabs for use when appliances are not used, or for use as night-splints.

(e) There may be increased spasm and pain, or fear of movement, and it is advisable to use valium (prescribed by doctor) at the beginning; decreasing and discontinuing its use as soon as possible during the day. Many children have spasm at night, and as rest is necessary for child and parent, it is often necessary to take measures to ensure this.

Re-assurance, support, if necessary total bodily support, are very often needed until a child becomes used to being without the support of the plaster.

Physiotherapy in Relation to the Hips, e.g. Adductor Transfer, Psoas Release, with or without Release of Rectus Femoris.

\section{Pre-operative therapy}

Conservative therapy aims at establishment of postural control in all basic motor developmental sequences. Mobility and stability of the hips is very often impaired due to muscle instability caused by spasticity or contracture of the hip flexors, adductors and internal rotators. Long-standing muscle imbalance may lead to subluxation and anteversion of the femoral necks with eventual dislocation. Surgery aims to correct muscle imbalance, and prevent bony deformity, or to correct deformity, when such has developed. *4

Early physiotherapeutic measures to prevent deformity include:

\section{Mobilisation of the hips}

From infancy this is done with the baby in supine, in flexion, bringing the toes to the mouth. This activity ensures spinal mobilisation as well as full external rotation and flexion/abduotion of the hips. It also helps to prevent the contracted, stiff hips sometimes seen in older children, where hip flexion contracture may be decreased by surgery. but the inability to fully flex the hips persists, with resultant flexion of the spine instead. The use of a Frejka pillow prevents adduction and effectively breaks up a total extensor pattern.

\section{Weight-bearing with corrected alignment}

In normal development, a baby starts taking weight from about five months of age onwards. Weight-bearing with the head of the femur located in the acetabulum is necessary for the development of a normal acetabulum and this process is completed by the age of four years.

In the presence of spastic adductors and psoas muscles, there is a tendency for the development of anteversion of the femoral neck, coxa valga and subluxation of the hip, with failure of acetabular development. It is therefore important that weight-bearing is encouraged even though the child is not neurologically matured. Measures used to correct alignment and prevent abnormal patterns when standing include:

1. Use of Forest Town Boot (or below-knee iron, with backstop) to provide plantigrade feet. In spite of heels riding up in boots with irons, the boot provides a plantigrade surface.

2. Roller between legs to ensure abduction and a wide standing base. 


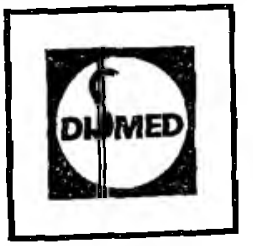

\section{THE \\ PRESENTS - Minidyne mk III TRANSISTORISED FARADIC UNIT}

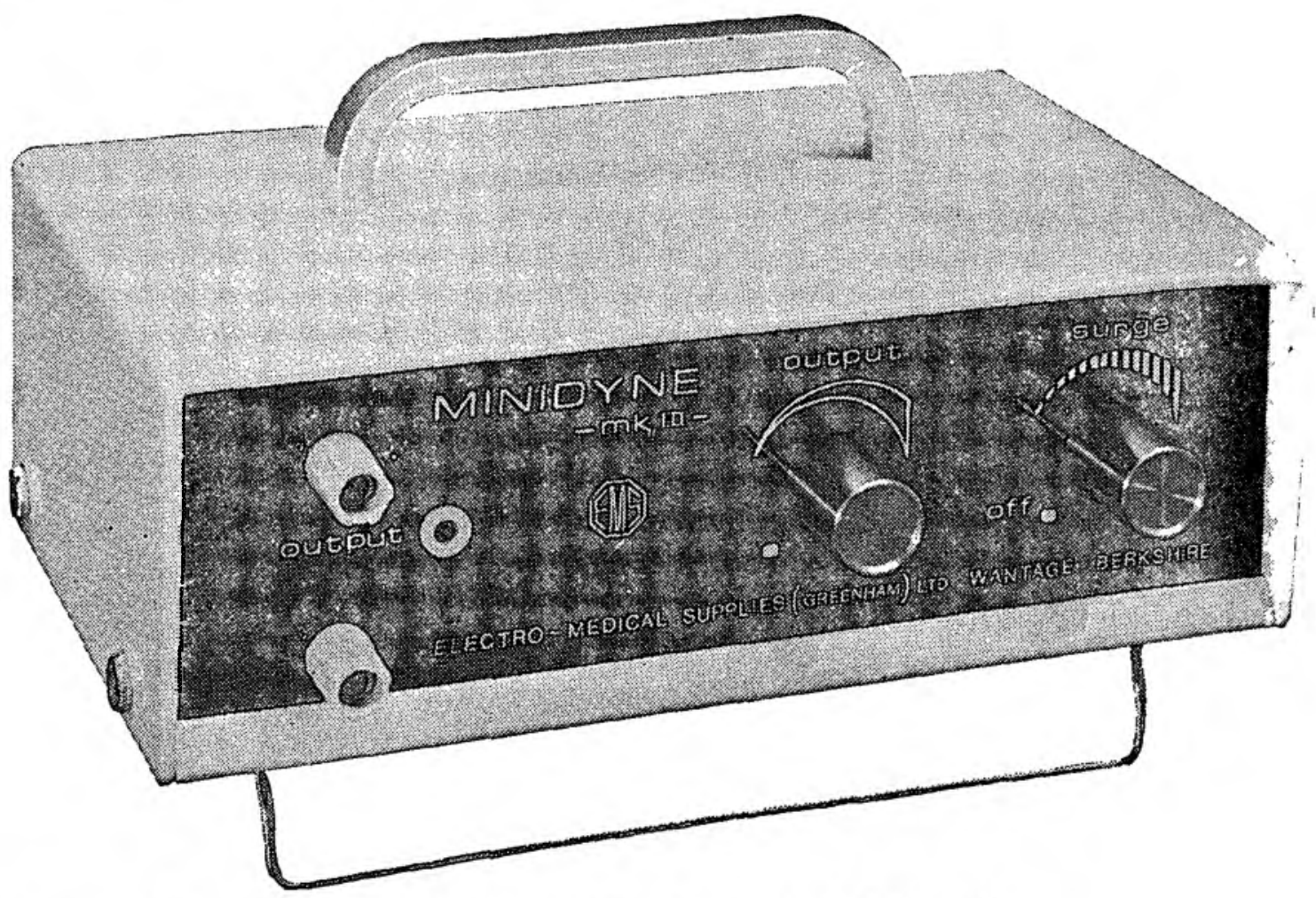

Representing another advance in the evolution of the Minidyne, the Mark III version incorporates printed circuits which reduce the size but also enhance the reliability continuing features are

wide range of surge speed control with output sufficient for all forms of faradic techniques

audible as well as visual indication of surge speed enabling the operator to anticipate a muscle reaction without having to watch the control panel

fitted with Ever Ready PP9 batteries which will give up to six months' use without replacement and are obtainable worldwide

PRICE:

$\mathbf{R} 96,50$

WEIGHT reduced to: $4 \mathrm{lbs}$. $(1,8 \mathrm{~kg})$

SIZE reduced to $8^{\prime \prime} \times 5 \frac{1}{2} " \times 2 \frac{1}{2} "(20 \mathrm{~cm} \times 13,5 \mathrm{~cm} \times 6 \mathrm{~cm})$. complete with accessories.

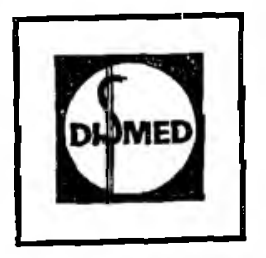

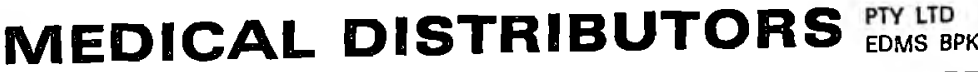

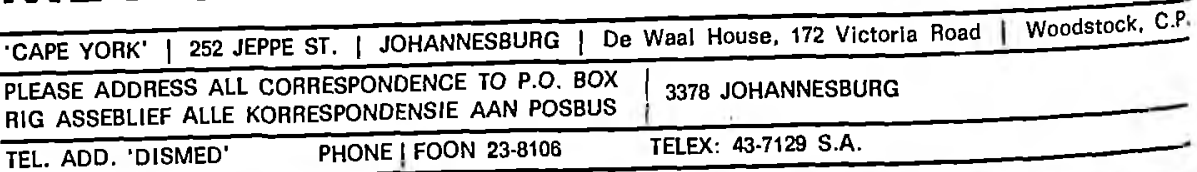


cases the ability to stand erect, even fully supported, without the spasm or contracture which was present pre-operatively, gives the child and his parents a great deal of pleasure and encouragement.

Postural training begins on the day after removal of plaster, and is given concommitantly with mobilisation and strengthening exercises.

cxircisc.

3. A dduction and external rotation of legs when doing excrises for arm *5

cruising sideways as the first step in walking. This a no

5. Abduction brace.

U. Usc of resistance to abduction (manual, springs or

6. Usc of rem) in the older child.

with dentil dam) in the of rectus femoris by using posi-

7. Milintain length of hip extension and knee flexion. lions anll movements should be improved as far as de8. Pelvic stabilily; it is dependent on:

furming forces muscle strength, extensors, abductors and Abdominal muscle

Wuctors in balance. Where tight hamstrings inter is often better in kneelin st.nding, pelvic there is no rectus femoris contracstanditits (urt).

In the presence of psoas contracture or rectus femoris inture, this posture will increase lumbar lordosis, 作 inch $7 m y$ be arms straight out in front of him.

4 Sic general pre-operative measures.

Pist-opirative Therapy

(Sic General Post-operative Measures, also removal of plister.)

After hip surgery, the patient may or may not be munhilised in a hip-spica. In any event sitting up will immorited after three weeks or after removal of plaster. he rartion now comprises:

1) Gicheral mobilisation. Passive movements (well within the limits of spasm or pain), assisted active and active movements, using developmental sequences, giving the child an opportunity to adapt to altered muscl: action and post-operative weakness, so increising confidence and strength without undue unxicty and strain. Whatever the child's pre-operative molor level, it is advisable to start again at the beginning. This progression through the developmental slate's may take children only a day or two in some ciac's, while others may take several weeks to regain the pre-operative development level. The time taken dicinds on the reaction to surgery and hospitalisaijul. Once this period of apparent retrogression has pilssed, one begins to see the benefits of surgery.

Support of the patient and parents during this limu is an important part of therapy. It is very wftull necessary to use a mild muscle relaxant/sedative for a while as well as counselling.

(b) Folluwing hip surgery, pelvic stability may initially se'n to be very poor, as mobility is usually greatly increised. With the removal of contractures, muscle billutic becomes a more realistic goal, although this mily, in some instances, take as long as three or four yeirs to achieve.

Ahdominal muscles are more easily facilitated in inner range, i.e. in positions of total flexion at first.

The ahductors of the hip which pre-operatively may uppear paresed must be assessed for spasticity and strengthened. Adduction and hip flexion are brought in und cmphasised in mid-position.

Full extension of the hips as well as external rotation will he more casily achieved post-operatively. Exercises ure given at first in non weight-bearing positions, then developmed to standing, using reflex inhibiting patterns in intal sequence.

These exercises are given without long calipers. Howcver, at the same time, while the child is wearing long (i) Stand or other splints, the following is started:

(i) Standing. with full support when necessary. In most (ii) Assisted walking (in calipers when necessary). This activity acts as an incentive to most children.

All the measures described under pre-operative therapy are used. Increased post-operative mobility will facilitate rotation which is given at first, in rolling, with or without resistance at hip or shoulder, then in the movement from four-foot kneeling to side-sitting and up to kneel-standing. If arm support is used, the hands should be in a flat supportive position, instead of grasping and pulling with the arms.

Half-kneeling may be a progression from step-standing, as the adductors, hamstrings and hip fiexors are stretched. This position should be achieved as soon as possible after surgery, and the lengthening maintained. Resistance to the pelvis anteriorly on the weight-bearing side, and laterally to the non weight-bearing knee, facilitates full extension of the weight-bearing hip and external rotation of the non weight-bearing knee.

Standing. It is easier to start standing up from sitting on a high stool, with hand support. The stool is lowered, to increase muscle work and postural control. Give approximation through the knees to facilitate quadriceps, and prevent the head from leading into total extension.

A great deal of sensory training (proprioceptive, kinaesthetic) is given with a great variety of slight postural changes and adjustments to accustom the patient to the altered centre of gravity and skeletal alignment. This is essentially sensori-motor learning. *6

Standing at first in parallel bars. using hands for support, in different positions. Weight transference, laterally as well as antero-posteriorly, and reciprocal arm movement precedes walking.

Walking starts in the parallel bars with hand support. This is progressed to walking with a rollator, crutches and sticks, or independent walking.

Trunk rotation is an important component of the walking pattern and is facilitated by resisted walking, the therapist resisting at the hips either anteriorly to increase fiexion, or posteriorly to increase extension and external rotation of the leg. Give downward approximation of the pelvis to increase extension. $* 7$

If there is a tendency to walk with flexed knees, the use of a gaiter or similar splint on the one leg ensures weight-bearing and extension of the hip on that side, while on the other leg one achieves hip extension in the inner range and knee extension in order to enable the gaitered leg to clear the ground.

The above measures apply to treatment in cases where locomotion is aimed for. In those cases where hip surgery is performed to facilitate nursing, treatment includes mobilisation, but not necessarily exercises in weightbearing positions.

When surgery is done to facilitate sitting, as in wheelchair cases, the programme is followed as far as is possible; a certain amount of pelvic stability is needed for sitting balance.

\section{Physiotherapy in Relation to Surgery of the Knee}

For Pre-operative measures, see under general preoperative requirements. Assess patients' disability. $* 8$

Post-operative Stage, in plaster of paris

1. Whether non weight-bearing, or in weight-bearing 
casts, emphasis must be on improving pelvic stability by strengthening the abdominals, extensors and abductors and external rotators of the hips.

Patients are often able to long-sit for the first time while in plaster after a hamstring release or lengthening. This may lead to excessive sitting and possible hip flexion contracture with weakening of hip extensors.

2. Prone-lying should be enforced for at least half a day.

3. Postural reactions are stimulated in standing between bars, also in assisted walking.

4. Posterior arm balance reactions and weight-bearing.

5. Back extension to correct kyphosis produced by previously tight hamstrings.

For Removal of Plaster - See General Post-operative page.

Post-operative Therapy follows the post-operative programme used while plaster casts are worn, including the following after removal of plaster of paris:

(a) Mobilisation, using passive, assisted active, active and resisted movements progressing through the developmental sequences.

In the older child knee flexion may be somewhat painful. Gradual flexion, using gravity over a pillow or over the edge of the bed, with voluntary extension of the knee, and prevention of flexor spasm in the unoperated hamstrings is a safe way of ensuring mobilisation. It is important to get flexion, as there may be spasm of the rectus femoris, which, if not alleviated or relaxed, rapidly leads to shortening and inability to flex the knees.

Four-foot kneeling, with roller supporting under abdomen and slow rocking, allows patient to mobilise himself.

(b) Bilateral calipers are worn initially until strength and control of muscles around the knee is sufficient to enable only one caliper to be worn. This is done on alternate legs until it can be discarded, or a lesser splint, e.g. gaiter, can be worn.

(c) Nightsplints should be used to maintain correction of deformity.

(d) Strengthening of

(i) hip musculature.

(ii) knee extensors, using sensory stimulation, resisted exercises, first in non weight-bearing, then in weight-bearing positions.

(e) Spasm of the rectus feinoris may be aggravated by the release of the hamstrings and the wearing of long calipers.

Prone lying with knee flexion and hip extension is useful to counteract this. As soor as the knees permit, weight-bearing exercises are given in half-kneeling and upright-kneeling. During the same period that mobilisation and strengthening exercises are given without calipers, the following is carried out while the patient is wearing calipers.

(i) Standing. supported or assisted. This is started on the first day,

(ii) Postural training, i.e. decreasing support to one hand, turning, reaching, bending etc.

(iii) Walking with calipers.

The essence of post-hamstring surgery treatment is the attainment of a balance between mobility of the knee, and controlled stability of the knee, without tight quadriceps muscles.

(i) Slow stepping on and off a stool, slow getting up and sitting down on a low stool are two practical home exercises.

Hyperextension of the knee is to be avoided, or corrected.

(ii) Re-education of the hamstrings is done if there is a tendency to rectus femoris spasm, or when laxity of knee ligaments predisposes to hyperextension of the knee.

Physiotherapy: Programme following Surgery to the
Ankle and Foot, with Particular Reference to: Gastro. cnemius Recession and Tendoachilles Z-Lengthening Pre-operative Measures see above for General Pre. operative aims. In particular:

1. Assess:

(a) Action of the anterior tibial muscle, as well as dorsiflexors of toes. Check whether extensor hallucis longue is being used as a dorsiflexor. Assess action of toe-flexors.

(b) Balance of eversion and inversion of foot.

(c) Strength of active plantarflexion.

(d) Presence of Positive supporting reflex (exaggerated).

(e) Presence of Withdrawal reflex. *9

(f) Strength and control of hip and knee extensors.

(g) Spasm or contracture of hip flexors, internal rotators or hamstring muscles; i.e. assess muscle balance around hip and knee and improve it if possible.

(h) Record any abnormality of sensation, or size of limbs (upper and lower extremity in case of hemiplegia).

Post-operative period.

This consists of three stages:

1. First three weeks in long or above-knee plaster-ofparis casts which are non-weightbearing.

2. The second three weeks, after removal of sutures, either long or short, below-knee casts which are weightbearing.

3. Period after removal of plasters.

1. During this stage, the therapist should take care that the muscle balance around the hip joints does not deteriorate, but improve it if possible. She should note any evidence of pain or pressure in the plaster.

2. During the second half of the wearing of a plaster cast, the cast may be above-knee in the presence of tight hamstrings or weak quadriceps, or it may be belowknee in the absence of the above-named. We find it useful to start with an above-knee cast, which we cut down below the knee as soon as control of weightbearing is achieved, and before we remove the plaster completely.

This allows time to work on the knee while the foot is still immobilised.

(a) Weight transference is taught; leg length being equalised by using temporary raises under other foot.

(b) Establish control of knee extension, in weight-bearing. Re-education of vastus medialis in sitting with knee flexed over edge of bed, and foot held in dorsiflexion in plaster. In addition all other metho of muscle stimulation and strengthening are usto (sensory stimulation and resistance) as well as the use of temporary splintage. $* 10$

After Removal of Plaster Casts

(a) Tendon lengthening very often has a widespread effect on the whole limb or body, in addition to the predictable expected localised effect.

In this way the extension-adduction pattern which is produced by an exaggerated positive supporting reaction may be so altered by a gastrocnemius recession and Tendo Achilles lengthening that abduction and knee flexion becomes possible, even in weight-bearing. In some cases a child may start to crawl post-operatively. whereas pre-operatively she could only creep, dragging extended legs, e.g. Case 3.

'Joanne, at two years old, was able to assume sitting position with knees flexed, not extended due to tight hamstrings. Her arm protective reactions were very slow. Sie could creep, dragging extended legs, but could noi crawl, as she had no dissociation of the legs. She triea to pull up standing, but could not take steps in the parallel bars, as she had co-contraction of the legs dut 
to a grossly exaggerated positive supporting reaction to wich made her stand with rigidly extended, adducted which and equinus feet.

Surgery performed: Bilateral Gastrocnemius Recession Tendo Achilles Z-lengthening. Six months later Ioanne was crawling, enjoying rolling, sitting much better, pulling up to standing and pushing a walker on her own. There has been a marked change in her emotional state; from being an introverted, frustrated, unhappy infant, she has changed to an outgoing, happy young child, eager to explore around her.'

Re-education of balance and equilibrium is therefore done, progressing through the different stages of development. Even where the postural reactions are good in standing, the confidence gained by the child while performing the basic gross motor activities of rolling, sitting, kneeling and crawling will enhance his progress in walking.

\section{Weight-bearing and Transference of Weight}

Gastrocnemius recession and Tendo Achilles Z-lengthening, by mechanically reducing plantarflexion and decreasing the effect of the positive supporting reaction, ifts the balance of power to the dorsiflexors of the unkle, thereby predisposing towards the total flexor pattern of the lower extremity.

To prevent post-operative 'folding up' or collapse into flexion with failure to weight-bear, pre- and post-operative therapy should establish control of extension of the hip and knee.

Sensory stimulation (icing, brushing, vibration) of the quadriceps, followed by active and restricted extension, is given alternatively with weight-bearing and assisted standing and walking in calipers. Initially, long calipers or gaiters are used bilaterally to assist extension. As soon as possible one caliper only is used on alternate legs, to give stability on that side with increased mobility on the other. Gaiters or any other temporary splints may be used. When control of the knees is satisfactory, below-knee irons with a back-stop and T-strap where necessary (to correct valgus or varus) is worn until dorsiflexor strength is adequate. Here a Forest Town Boot may be used instead; this has the added advantage of stretching the long toe flexors.

(a) Refusal to stand may be due to:

(i) presence of a withdrawal reflex, which may previously have been masked by the positive supporting reaction.

Flexion should be prevented mechanically until this is overcome. Begin by standing up (with hand support) from sitting and stepping up and down from a low stool, therapist manually assisting extension.

(ii) Hyper-sensitivity of sole of foot. The skin should te de-sensitised by brushing, hardening the skin etc.

(iii) Painful heel. A child who has never walked with heelstrike may have no insulating layer of thick skin and subcutaneous tissue over the calcaneous to cushion the shock of weightbearing on the heel. A resilient heel-pad will overcome this problem.

(b) Establish muscle balance around the ankle, mainly by:

(i) increasing strength of dorsiflexors.

Initially it may be possible only to get active contraction of the tibialis anterior by facilitation of dorsiflexion in a mass pattern of flexion (i.e. with knee and hip flexed). This should be cbanged to dorsiflexion of the ankle with extended knee (for heelstrike) as soon as possible.

Facilitation of contraction is greatly improved by sensory stimulation using ice, brushing, vibration, friction, followed by active and resisted active movement. (ii) Prevent dorsiflexion of ankle by excessive contraction of extensor hallucis longus; isolate action of Tibialis anterior by repeated contractions of anterior tibial in inner range holding the big toe in flexion while activating dorsiflexion.

(iii) Extension of the toes with the foot in dorsiflexion to overcome any tendency of clawing.

(iv) Maintenance of lumbrical action, especially when a Forest Town Boot is worn for a long time.

(v) When dorsiflexor strength is adequate, plantảrflexion is strengthened to allow push-off in walking.

(vi) Balancing the action of the evertors and invertors of the foot.

The above exercises are done with resistance, in modified patterns using proprioceptive neuromuscular facilitation, and ideally also in the weight-bearing position.

(c) Early weight-bearing, whether supported or assisted, is very important, as the upright position, with the head vertical, and compression of the joints, added to the positive supporting reaction, increases extensor tone and postural reflex activity. If a child is allowed to be non weight-bearing for too long, especially if there is a tendency to flexor hypertonus, then there is a danger that the flexors of the hip, knee and ankle may become overactive and preclude muscle-balance. Calcaneous deformity may result.

Weight-bearing in a corrected standing position is a good way of preventing this 'shift' of spasticity.

(d) Gait-training; with emphasis on

(i) transference of weight to equalize weight-bearing.

(ii) establishing trunk rotation.

(iii) prevention of hyperextension of knee.

Resisted (from behind and in front) rotational walking is effective.

Standing and walking progresses from the use of parallel bars to rollator walker, then elbow crutches or tripod sticks, which may later be discarded.

(e) Balance reactions of the feet in standing and walking, e.g.

(i) balancing on a roller,

(ii) standing on one leg, using other foot to roll around a large ball; without losing contact with the ball.

\section{References}

* I Bobath, B., Bobath, $K$. 'The Facilitation of Normal Postural Reactions and Movements in the Treatment of Cerebral Palsy. Physiotherapy August 1964.

* 2 Reynell, J. K. (1965). 'Post-operative Disturbances observed in children with Cerebral Palsy'. Dev. Med. Child Neurology, 7, 360-376.

* Craig, J. J. 'The Orthopaedic Approach to the Treatment of Cerebral Palsy. S. African Medical Journal 47, 1973, p. 1904.

* Bleck, E. "Management of Hip and Knee Deformities' Cerebral Palsy. Current Practice in Orthopaedic Surgery. Vol. 3, p. 59. Edited by J. P. Adams. St. Louis. The C. V. Mosby Co.

- 5 Bobath, B. 'The Very Early Treatment of Cerebral Palsy. Dev. Med. \& Child Neurology. Vol. 9, No. 4, 1967.

* Peiper, $A$. 'Cerebral Function in Infancy and Childhood.' Pitman Medical 1963, pp. 230-236. Locomotion, p. 211.

* 7 Knott, M., Voss, D. E. (1969). 'Gait Activities.' Proprioceptive Neuromuscular Facilitation. Harper \& Row Publishers, New York City. 


\section{MAKE YOUR DAY A LITTLE EASIER!}

You physios are a hard-worked group, we know. In the day's work, environment and comfort become more and more important - and while there's not much we can do to help fix the background in which you work, you'll find a comfy, practical working rig in the new specialpurpose uniform we ve designed with you in mind.

It's a continental style dress, with Bermuda-type shorts to match. A side vent in the skirt and the generous cut, mean that you'll work more easily, and feel comfortable right through the hard day.

Your option of short or long sleeves, in drip-dry, hard-wearing fabric... white or saxe blue. Sizes 32 to 42 .

Elegance and efficiency ... what more could you ask?

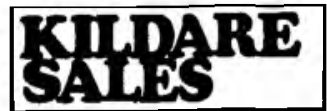

$4^{\text {th }}$ Floor, Pritchard House, 83 Pritchard Street, JOHANNESBURG. Telephone 23-4405.

87 Marion Avenue, Glenashley, DURBAN. Telephone 83-7226.

Fully illustrated catalogues and price lists of our full range are available free to you. Just drop us a postcard (P.O. Box 752, Johannesburg) or telephone 23-4405 any time, including nights, weekends and holidays. We're also happy to execute phone orders, of course. 
* s Burke Evans, E. 'Modifications of the Hamstring Transfer.' Developmental Medicine \& Child Neurology Vol. 8, Oct. 1966, p. 539-551.

* Twitchell, T. B., Ehrenreich, D. L. 'The Plantar Response in Infantile Cerebral Palsy.' Developmental Medicine \& Child Neurology' 1962, Vol. 4, p.602-11.

-10 Rood, Margaret. 'Personal Communication' 1969. Instructional Course. Johannesburg.

* Craig, J. J. 'The Correction of Equinus Deformity in Cerebral Palsy'. Paper read at Annual Congress of American Academy of Cerebral Palsy, Washington, December 1974.

\section{NOTE ON THE FOREST TOWN BOOT}

This appliance evolved as a result of the combined efforts of the physiotherapy staff at Forest Town School, the Consultant Orthopaedic Surgeon and the Orthopaedic Technicians at the Johannesburg General Hospital.

The object of the boot is to prevent tightening of the Tendo Achilles and lengthening of the dorsiflexors while enabling a child with an over-active positive supporting reaction to walk.

In the boot the ankle is held at an angle of $90^{\circ}$, the toes are in extreme dorsiflexion, there is no pressure on the metatarsal heads (the boot being recessed here) and the calcaneus is well down.

\section{Discussion}

1. The most obvious effect of the boot is the continuous stretch produced on the triceps surae muscle group (particularly soleus) and the toe flexors producing what might be described as a lengthening reaction in these muscles. Whatever the neuro-physiological reaction, this does in fact appear to take place to a considerable extent.

2. The removal of pressure from the metatarsal heads was considered an important attribute of the boot when it was thought that this area was the optimal site of stimulation of the positive supporting reaction. It was subsequently thought (Twitchell 1962) that the adequate stimulus for the positive supporting reaction was not pressure but proprioceptive stretch of the plantar muscles or triceps surae. This is also eliminated as the boot allows no movement at the ankle. However, we continue to use the boot recessed over the metatarsal reads as we have found that pressure here does neverdeless play some part in increasing the activity of the positive supporting action.

3. Most of the weight is taken on the calcaneus while the boot is worn. There appears to be facilitation of the Anterior Tibial muscle group.

4. The dorsiflexors are held in inner range while the boot is worn instead of being lengthened as happens with the foot in constant plantar flexion. Thus activation of the dorsiflexors is much easier. The boot is worn from infancy to prevent any lengthening of the anterior tibials.

\section{Other Clinical Advantages}

1. In a patient with the typical abductor circumduction gait of hemiplegia, the walking pattern is facilitated by the breaking up of total pattern brought about by wearing the boot.

2. The boot serves to control the position of the foot in the therapy when more proximal patterns are being executed.
3. The boot is used both pre- and post-operatively as a night splint.

4. The boot is worn post-operatively whenever there is a sign of recurrence of muscle imbalance around the ankle. The patient walks with a Forest Town Boot for a few hours every day, and needs no other appliances. Recurrence rate of deformity after surgery is therefore reduced. *11

5. The boot provides a plantigrade foot as a base, instead of an equinus foot, and makes standing balance and learning to walk much easier.

\section{Comment}

The child is usually first accustomed to wearing the boot as a night splint. Some children do not sleep through the night at first and parents have to use their discretion in lengthening the periods of use.

Generally speaking, the boot is most effective when used for walking in. This is also started very gradually, inspecting for signs of pressure at lengthening intervals. When ordered bilaterally, it may be advisable to get the child used to walking with one at first, with an ordinary boot on the other foot. However, most children tolerate the boots very quickly.

There may be a tendency, initially, for a child to either flex or hyperextend the knee, as the boot stretches the spastic triceps surae. Judicious use usually overcomes this problem speedily.

Children with fixed contracture cannot tolerate the boot; and children with gross spasm of the triceps surae may not be able to tolerate them for weightbearing until they have slept in them for a length of time.

\section{More stamps for more Cripples}

Fourteen million colourful Easter Stamps have been printed by the National Council for the Care of Cripples for its 30th annual Easter Stamp Fund campaign, which will be conducted during March, 1974 to raise funds in aid of cripples of all races in the Republic and South West Africa. This means four million more stamps than issued for any of the Council's previous campaigns.

The stamps will be offered for sale in sets of 20 in the popular series depicting South Africa's maritime history in full colour and introduced in the 1973 campaign.

This new set is available in sheets containing a single set of 20 stamps or five sets of 20 stamps and will be sold at only one cent per stamp. They are obtainable, together with sheets of interesting information about each of the 20 ships printed on the stamps, from all Cripple Care Association offices or from The Director, National Council for the Care of Cripples in South Africa, P.O. Box 10173, Johannesburg 2000 (telephone 31-5151). 